\title{
Editor's Introduction to the first issue of JRACR
}

This inaugural issue formally announces the establishment of the international Journal of Risk analysis and Crisis Response (JRACR) to disseminate research findings and applications on a variety of topics in risk analysis (RA) and improved crisis response (CR). The Advisory Board and Editorial Board consist of internationally acclaimed scholars in their respective fields, who bring their combined talents to bear on critical challenges in $R A$ and $C R$, coming from universities, companies, government agencies and non-governmental organizations in 21 different countries.

Today, we live in a high-risk society with more insecurity and greater challenges than ever. Risk, associated with a future incident accompanied by some adverse effect ${ }^{1}$, not only arising from natural phenomena but also produced by human activity, has become everywhere linked to potentially more destructive outcomes. Our ability to collect information, form knowledge and control systems has been unable to keep up with the speed of change in the world.

RA has been currently used to analyze future events characterized by uncertainty that may involve deleterious consequences, whether caused by natural forces or by human short-sightedness and negligence. CR has reached an advanced level in saving lives, reducing losses and preventing the deterioration of perilous situations.

So far, no theory can fully explain risks; no technology can cope with every complex crises. The presence of multiple potential threats stimulates the development of new theories and methods for risk analysis. The pursuit of more effective responses to crisis situations requires a continuous improvement of $\mathrm{CR}$ technology. The goal of JRACR is to enable scientists, engineers and technical officers to share research results and valuable experience, to build a foundation for a better tomorrow.

This issue contains eight papers. Five contributions are written in English and the remaining are in Chinese with English abstracts. The papers can be divided into four categories: emerging risk, crisis planning, environmental risk and disaster risk.

In the first category, the paper "Biogas - A European Perspective on Safety and Regulation" by Salvi, Delsinne and Evanno ${ }^{2}$, presents a review of the situation on biogas production and uses, and points out that proper safety management and adequate regulation will ease the quick deployment of this technology, but there are still some issues to be solved. The paper "Towards the Development of Regional Risk Profiles and Adaptation Measures for Sea Level Rise" by Ayyub and Kearney ${ }^{3}$, discusses the sea level threat posed by global warming and suggests a framework for quantifying the risk for addressing many of the aspects of the sea level challenge, especially coastal infrastructure. 
The second category includes one paper "Risk Individuality in Crisis Planning: the Case of Gender in Amercan Agriculture" by Hoag, Keske and Goldbach ${ }^{4}$, shows that, in some cases, it is possible to improve crisis response when we consider differences in risk perception. For example, women were more risk averse and less confident in a case study of agricultural producers in the USA.

There are two papers in the environmental risk category. The paper "Fuzzy Multicriteria Risk Assessment for Hazardous Waste Management: The Case of Istanbul" by Uğurlu and Kahraman ${ }^{5}$, suggests a multicriteria evaluation method for various hazardous waste treatment alternatives. Under the main criteria, economic, risks, and technical, the authors consider 11 sub-criteria. The paper "Airborne Levels of Uranium in the Surroundings of Various Industrial Facilities: Human Health Risks" by Rovira, Linares, Bellés, Nadal and Domingo ${ }^{6}$, analyzes the airborne concentrations of natural uranium in the vicinity of different industrial plants of Catalonia, Spain. The health risks associated to the exposure to this element through air inhalation were also assessed for adult people living close to those facilities.

There are tree papers in the disaster risk category. The paper "A Discrete Model of the Expected Loss for Catastrophe Insurance in Natural Disasters" by Huang and $\mathrm{Shi}^{7}$, suggests a discrete model of catastrophe insurance to calculate the expected losses. It was successfully applied to calculate the premium rate of the typhoon in Fujian Province, China. The paper "The Risk Assessment of the Fog Disaster in Beijing" by $\mathrm{Hu}$ and $\mathrm{Pan}^{8}$, assesses the fog disaster risk in Beijing by spatial grid with recent 10 years observatory data. The result indicates that the high risk area is consistent to the extending of highway and ring-roads, as parts of urban center area and airport, and so on. The paper "The Combustible Materials Remote Sensing Ration Calculation and Fire Risk Dynamic Monitor in the Seasons of Withered Grass in Xilingoule Grassland" by Zhuo, Liu and $\mathrm{Yu}^{9}$, suggests a fire risk index from the superposition of the meteorological drought index, the combustible stock, vegetation continuous and snow conditions to express the risk level of surface fuel.

We sincerely hope our reader will find this issue's information on RA and CR useful, and we warmly invite readers around the world who are committed to research and practice in $\mathrm{RA}$ and $\mathrm{CR}$ to submit their quality papers to this journal for dissemination of their vital contribution for constructing a safer world!

Chongfu Huang

JRACR Editor-in-Chief

References

[1] C.F. Huang and D. Ruan. Fuzzy risks and an updating algorithm with new observations. Risk Analysis, 28(3) (2008) 681-694.

[2] O. Salvi, S. Delsinne and S. Evannod. Biogas - A european perspective on safety and regulation. J ournal of Risk Analysis and Crisis Response, 1(1) (2011) 1-20.

[3] B.M. Ayyub and M. Kearney.Towards the development of regional risk profiles 
and adaptation measures for sea level rise. Journal of Risk Analysis and Crisis Response, 1(1) (2011) 75-89.

[4] D. Hoag, C. Keske and R. Goldbach. Risk indviduality in crisis planning: the case of gender in Amercan agriculture. Journal of Risk Analysis and Crisis Response, 1(1) (2011) 21-28.

[5] S. Uğurlu and C. Kahraman. Fuzzy multicriteria risk assessment for hazardous waste management: the case of Istanbul. Journal of Risk Analysis and Crisis Response, 1(1) (2011) 29-41.

[6] J. Rovira,V. Linares, M. Bellés, M. Nadal and J. L. Domingo. Airborne levels of uranium in the surroundings of various industrial facilities: human health risks. Journal of Risk Analysis and Crisis Response, 1(1) (2011) 42-47.

[7] C.F. Huang and S X. Shi. A discrete model of the expected loss for catastrophe insurance in natural disasters. J ournal of Risk Analysis and Crisis Response, 1(1) (2011) 48-58.

[8] H.B. Hu and J.J. Pan. The risk assessment of the fog disaster in Beijing. Journal of Risk Analysis and Crisis Response, 1(1) (2011) 59-64.

[9] Y. Zhuo, G.X. Liu and F.M. Yu. The combustible materials remote sensing ration calculation and fire risk dynamic monitor in the seasons of withered grass in Xilingoule Grassland. Journal of Risk Analysis and Crisis Response, 1(1) (2011) 65-74. 